\title{
Evaluation of Serum Immunoglobulins IgG, IgA, IgM and Total IgE in Chronic Alcoholics: A Community-based Study
}

Yashwant Kumar ${ }^{1^{*}}$, Lakshmi PVM², Ranjana Walker Minz ${ }^{1}$, Seema Chhabra ${ }^{1}$ and Biman Saikia ${ }^{1}$

${ }^{1}$ Department of Immunopathology, Post Graduate Institute of Medical Education and Research, Chandigarh, India

${ }^{2}$ School of Public Health, Post Graduate Institute of Medical Education and Research, Chandigarh, India

\begin{abstract}
Long-term intake of alcohol affects virtually every organ in the body including the immune system. The relation between alcohol abuse and immunoglobulin production has not been studied in Indian population. Serum levels of immunoglobulins (total $\lg \mathrm{E}, \lg \mathrm{G}, \lg \mathrm{M}$, and $\lg \mathrm{A}$ ) therefore, were analyzed in adult chronic alcoholics and were correlated with different epidemiological and alcohol-related parameters. The results showed that $98 \%$ of alcoholics had abnormal immunoglobulin levels and $92 \%$ showed high or very high total serum IgE levels compared to $24 \%$ of the control group. Long term and moderate consumption of alcohol were also associated with frequent infections. Serum immunoglobulin assay including total lgE may be helpful in screening and assessment of chronicity of alcohol abuse.
\end{abstract}

Keywords: Alcohol; Immunoglobulins; Total IgE; Total IgG; Total IgA; Total IgM

\section{Introduction}

Long-term intake of alcohol besides having psychosocial and financial impact imposes serious health problems [1].It affects virtually every organ in the body including immune system [2]. Besides leading to development of liver disease, pancreatitis, heart and neurological problems, chronic alcohol intake is now recognized as common cause secondary immunodeficiency that in turn may cause frequent infections [3]. Alcohol abuse interferes with the host's immune surveillance system and leads to diminished humoral and cell-mediated immune responses against infections. It has been documented in the past that chronic alcohol consumption may alter B cell numbers and causes hypergammaglobulinemia possibly due to antigenic stimulation of $\mathrm{B}$ lymphocytes [4]. However, except total IgE, conflicting results have been shown regarding individual immunoglobulins [5-9].

Alcohol abuse is a growing problem of India with a prevalence of moderate to heavy alcohol consumption of $21.4 \%$ [10]. In addition more than half of all Indian drinkers fall into the criteria for hazardous drinking, which are characterized by bingeing and solitary consumption to the point of intoxication [11]. With such heavy consumption of alcohol there is a probability of high prevalence of alcohol-related problems like immune imbalance or immunodeficiency. Though literature is available on levels of immunoglobulins in alcoholics but still studies are limited and there is hardly any work comparing the levels of all immunoglobulins together (IgG, IgA, IgM and total IgE) in these individuals. Moreover, results of these immunoglobulins in Indian alcoholics have not been reported so far. This small preliminary study, therefore, makes an effort to assess the serum levels of immunoglobulins IgG, IgA, IgM and total IgE in alcoholics of the Northern region of India.

\section{Methods}

\section{Selection of study group and sample collection}

In a case-control study, adult chronic alcoholics, otherwise apparently healthy volunteers from general population of Chandigarh (UT) were offered a pre-designed questionnaire and interviewed by a medical/research officer to assess the severity of alcohol abuse and any associated morbidity. Information regarding age at first intake of alcohol, duration of alcohol consumption, type and amount of beverage, rate of infections and other illness were collected followed by an Alcohol Use Disorders Identification Test (AUDIT) score to assess the physical dependency.

Individuals were also enquired about any symptoms pertaining to allergic disorders and episodes of infections (bacterial, viral or parasitic). The information was documented in a separate proforma. Fifty alcoholics who agreed to participate in the study were recruited. Fifty non-alcoholic, age and sex matched volunteers from the same population were also included as control subjects. Volunteers with a history of previous episode(s) of allergy or symptoms related to infections particularly parasitic e.g., presences of worms in stools, were excluded from the study. After an informed written consent from the study participants, about 2-3 ml venous blood was collected in a plane vacutainer taking all aseptic precautions. The samples were immediately delivered to Immunopathology Lab where serum was separated after centrifugation and stored at $-20^{\circ} \mathrm{C}$ till the time of analysis. Hemolyzed samples were excluded from the study.

\section{IgG, IgM, IgA and total IgE assays}

Nephelometry was done for determination of $\operatorname{IgG}, \operatorname{IgM}$ and IgA using commercially available kits (MININEPH, Binding site, Birmingham, UK). Serum samples and reagents were brought to room temperature immediately before analysis. The samples were diluted in 1:11 ratio $(40 \mu \mathrm{l}$ of sample in $400 \mu \mathrm{l}$ of diluent). Thereafter, samples (10 $\mu \mathrm{l}$ for IgG and $40 \mathrm{l}$ for IgM and IgA) were mixed with $400 \mu \mathrm{l}$ of buffer and $40 \mu \mathrm{l}$ of anti-immunoglobulin in a cuvette already placed on cuvette holder on Nephelometer and readings were noted. Serum

*Corresponding author: Yashwant Kumar, Department of Immunopathology, Post Graduate Institute of Medical Education and Research, Chandigarh, India, Tel: 8437220033; E-mail: dryashwant@ymail.com

Received September 14, 2015; Accepted September 28, 2015; Published October 04, 2015

Citation: Kumar Y, Lakshmi PVM, Minz RW, Chhabra S, Saikia B (2015) Evaluation of Serum Immunoglobulins IgG, IgA, IgM and Total IgE in Chronic Alcoholics: A Community-based Study. Immunochem Immunopathol 1: 102. doi: 10.4172/24699756.1000102

Copyright: ( 2015 Kumar Y, et al. This is an open-access article distributed under the terms of the Creative Commons Attribution License, which permits unrestricted use, distribution, and reproduction in any medium, provided the original author and source are credited. 
levels of $\operatorname{IgG}$, IgM, and IgA were taken as normal when they measured between $658-1837 \mathrm{mg} / \mathrm{dl}, 40-263 \mathrm{mg} / \mathrm{dl}$ and $71-360 \mathrm{mg} / \mathrm{dl}$ respectively.

Total IgE levels were measured using ELISA kit (IMMUNOLAB $\mathrm{GmbH}$, Kassel, Germany) as per manufacturer's instructions. Optical densities were determined using an ELISA reader and levels of total IgE were calculated using standard curves performed for ELISA plate. A value of $\geq 100 \mathrm{IU} / \mathrm{ml}$ was considered as raised total serum IgE levels. Results obtained were correlated with various parameters including age, diet, infection episodes, amount and duration of alcohol consumption, type of beverage and AUDIT score.

\section{Statistical analysis}

Statistical analysis was performed with SPSS version 20 (SPSS, Chicago, IL). Association between alcohol consumption and continuous variables i.e., immunoglobulin levels was analyzed by Independent t-test and Mann-Whitney test. Mean, range and standard deviation were used for nonparametric variables. A $p$-value $<0.05$ was considered statistically significant.

\section{Results}

All alcoholics were males with mean age of 39 years (range 1963 years) compared to 35 years (range 24-51 years) in controls (40 males, ten females). Five cases were young and unmarried, and 46 (92\%) were non-vegetarian. Seventy-six percent (38/50) were chronic alcoholics consuming alcohol for $>10$ years. Sixty-eight percent of these (34/50) were heavy drinkers consuming $>250 \mathrm{ml} /$ day and frequently amounting to unstoppable drinking (Table 1). Sixty-two percent $(31 / 50)$ were even unable to work after alcohol intake. AUDIT score among the alcoholics was $>30$ in $6,16-30$ in 32 , and $<16$ in 12 cases indicating heavy, moderate and mild physical dependency among them respectively. Concern about alcohol abuse and guilt feeling was also found in $82 \%$ (41/50) of the cases.

Two of them had tuberculosis while 3 were hypertensive. Sicknessrelated to infections was seen in $28(56 \%)$ cases with fever being the commonest symptom (32\%) followed by a cough (25\%), diarrhea (14\%) and jaundice (7\%). Of the symptomatic individuals, $28 \%$ developed one or more of the above symptoms almost every month while $39 \%$ had at least one episode every year. The other $33 \%$ fell sick after every six months. Forty-three percent of such individuals had either completed or were on treatment for infections or related symptoms. Thirtysix percent (18/50) also got injured at least once as a result of heavy drinking.

One or more immunoglobulins (IgG, IgA, IgM, and total IgE) were abnormal (low or high) in all except one alcoholic (98\%) compared to controls (44\%). A predominant increase was noted in all immunoglobulins except a decrease in IgM levels in $6 \%$ of cases. All four immunoglobulins (IgG, IgA, IgM, and IgE) were raised only in $8 \%$ of the cases while 2 or more immunoglobulins were increased in $70 \%(35 / 50)$ cases compared to $22 \%(11 / 50)$ in controls. Isolated immunoglobulin increase (IgG, IgM or IgA) was seen in $20 \%(10 / 50)$ of alcoholics compared to $18 \%(9 / 50)$ controls. High IgG levels were seen in $56 \%$ (versus $30 \%$ controls), IgA in $26 \%$ (versus $12 \%$ controls), and IgM in $16 \%$ cases (versus $4 \%$ controls). IgG, IgA and IgM elevation was more common in alcoholics compared to controls. However, the increase could not achieve statistically significant value (Table 2).

An imperative observation was a statistically significant rise in total IgE levels in $92 \%$ of cases (Table 2; Figure 1). In comparison only $24 \%$ of controls had high total IgE levels ( $\mathrm{p}$-value 0.0001 ; independent t-test). Besides this, the concentration of total $\operatorname{IgE}$ was very high in those consuming alcohol $(>1000 \mathrm{IU} / \mathrm{ml})$ compared to control subjects who had only borderline increase $(<500 \mathrm{IU} / \mathrm{ml})$ (Figure 2$)$.

On correlating the immunoglobulins levels with nonparametric variables among alcoholics, high IgE levels were found to be associated with non-vegetarian diet, smoking, frequent infections, frequent and heavy drinking and high AUDIT score (Table 1). In control subjects also raised immunoglobulin levels were associated with smoking and non-vegetarian diet. IgG too showed a pattern similar to IgE except that those taking $<80 \mathrm{ml} /$ day had normal IgG levels. IgA levels were associated with non-vegetarian diet, smoking, and Desi Sharab (locally prepared) than another type of drinks. Raised IgM levels were seen in $16 \%$ cases only.

\section{Discussion}

The study provides important information on immunoglobulin status after prolonged and excessive intake of alcohol in Indian adult population. A positive association was found between smoking, nonvegetarian diet and heavy alcohol consumption. Immunoglobulin levels were abnormal in those with regular, moderate and heavy alcohol consumption and the majority of these alcoholics were consuming either whiskey or Desi Sharab both of which contain a high quantity of alcohol.

In the past studies, smoking has been proved to alter serum immunoglobulin levels $[12,13]$. It has been shown that serum IgG and IgA levels are lower in smokers as compared to non-smokers with minimal effect on IgM levels [14]. This is in contrast to alcoholics in our study who showed raised IgG and IgA levels. Hence it is unlikely that in the present study smoking influenced the serum $\operatorname{IgG}, \operatorname{IgA}$ and IgM values. On the contrary, alcohol and smoking both increase total IgE levels. But the effect of smoking probably is minimal since $2 / 3^{\text {rd }}$ of smokers in a study by Bahna et al. though had higher total IgE compared to non-smokers but the levels were within normal range $(<100 \mathrm{IU} / \mathrm{ml})$. On the contrary, heavy smokers showed a drop in IgE [15]. This could be an explanation for higher mean value of total IgE in non-smokers than smokers observed in our study.

Despite high total IgE, the mean value was lesser in nonvegetarians than in vegetarians. This could be because of the fact that non-vegetarian alcoholics were more in number (46/50 nonvegetarians versus $4 / 50$ vegetarians) and among them few had only mild elevation in total IgE whereas, vegetarians were very few and had higher IgE levels. This could have resulted in wide variation and lower mean value in non-vegetarians. On the whole, the diet alone hardly has any impact on immunoglobulin levels [16]. In the present study whether the association between non-vegetarian food, alcohol and immunoglobulins is true or an effect of chance remains to be confirmed.

The mean value of total IgE was higher in heavy drinkers $(>500 \mathrm{ml} /$ day) compared to moderate drinkers $(<500 \mathrm{ml})$. Another group which showed a marginal increase comprised of those with an intake between $100-250 \mathrm{ml} /$ day. The reason for this may be the long term effect of alcohol as many of these were consuming 100-250 ml/day for 10-20 years.

Chronic alcoholics also had frequent episodes of infections in the form of fever, cough, and diarrhea, etc. Though the study subjects were enquired for different type of infections (e.g., presenting with fever, cough, respiratory distress, increased frequency and burning micturition, duration and type of diarrhea, passage of worms in stool etc), the exact type of infections could not be confirmed. Among 
Citation: Kumar Y, Lakshmi PVM, Minz RW, Chhabra S, Saikia B (2015) Evaluation of Serum Immunoglobulins IgG, IgA, IgM and Total IgE in Chronic Alcoholics: A Community-based Study. Immunochem Immunopathol 1: 102. doi: 10.4172/2469-9756.1000102

Page 3 of 5

\begin{tabular}{|c|c|c|c|}
\hline Variables & $\begin{array}{c}\text { Alcoholics } \\
(n=50)\end{array}$ & $\begin{array}{c}\text { Total lgE } \\
\text { Mean (range) }\end{array}$ & $\begin{array}{c}\text { High IgE } \\
(\ln \%)\end{array}$ \\
\hline $\begin{array}{c}\text { Diet } \\
\text { Non-vegetarian } \\
\text { Vegetarian }\end{array}$ & $\begin{array}{c}46 \\
4\end{array}$ & $\begin{array}{c}1348(<50->10000) \\
1752(70-5611)\end{array}$ & $\begin{array}{l}89.1 \\
50.0\end{array}$ \\
\hline $\begin{array}{c}\text { Smoking } \\
\text { Yes } \\
\text { No } \\
\text { No information provided }\end{array}$ & $\begin{array}{l}24 \\
11 \\
15\end{array}$ & $\begin{array}{c}1393(56->10000) \\
1728(45-5611) \\
-\end{array}$ & $\begin{array}{c}94.3 \\
81.8 \\
-\end{array}$ \\
\hline $\begin{array}{c}\text { Frequent infections } \\
\text { Yes } \\
\text { No } \\
\text { No information provided }\end{array}$ & $\begin{array}{c}28 \\
2 \\
20\end{array}$ & $\begin{array}{c}1722(45->10000) \\
336(56-280) \\
-\end{array}$ & $\begin{array}{c}93.3 \\
6.6 \\
-\end{array}$ \\
\hline $\begin{array}{c}\text { AUDIT score } \\
\quad<16 \\
>16\end{array}$ & $\begin{array}{l}12 \\
38\end{array}$ & $\begin{array}{l}786(56->10000) \\
1591(45-10000)\end{array}$ & $\begin{array}{l}83.3 \\
92.1\end{array}$ \\
\hline $\begin{array}{l}\text { Frequency of drink } \\
\text { Less than } 4 \text { times/week } \\
\text { More than } 4 \text { times/week } \\
\text { No information provided }\end{array}$ & $\begin{array}{c}3 \\
42 \\
5\end{array}$ & $\begin{array}{c}2530(86-7653) \\
2468(45->10000) \\
-\end{array}$ & $\begin{array}{c}66.6 \\
92.8 \\
-\end{array}$ \\
\hline $\begin{array}{c}\text { Amount of drink/day } \\
<100 \mathrm{ml} \\
100-250 \mathrm{ml} \\
250-500 \mathrm{ml} \\
>500 \mathrm{ml}\end{array}$ & $\begin{array}{c}3 \\
13 \\
13 \\
21\end{array}$ & $\begin{array}{c}3754(170-8696) \\
1339(80->10000) \\
1009(56->10000) \\
1277(<50->10000)\end{array}$ & $\begin{array}{l}100 \\
92.3 \\
84.6 \\
90.5\end{array}$ \\
\hline $\begin{array}{c}\text { Duration of drinking } \\
<10 \text { years } \\
10-20 \text { years } \\
>20 \text { years } \\
\text { No information provided }\end{array}$ & $\begin{array}{c}9 \\
28 \\
10 \\
3\end{array}$ & $\begin{array}{c}3177(153-8696) \\
680(53->10000) \\
1767(45-6639) \\
-\end{array}$ & $\begin{array}{c}100 \\
89.2 \\
80.0 \\
-\end{array}$ \\
\hline $\begin{array}{l}\text { Type of liquor } \\
\text { Whisky } \\
\text { Desi sharab } \\
\text { Other } \\
\text { All }\end{array}$ & $\begin{array}{c}23 \\
16 \\
6 \\
5\end{array}$ & $\begin{array}{c}1212(<50->10000) \\
1805(45->10000) \\
1638(56-8696) \\
2363(53->10000)\end{array}$ & $\begin{array}{l}95.6 \\
93.7 \\
66.6 \\
80.0\end{array}$ \\
\hline
\end{tabular}

Table 1: Correlation of total IgE with various parameters among the alcoholics.

\begin{tabular}{|c|c|c|c|c|c|c|c|}
\hline \multirow{2}{*}{ Immuno-globulins } & \multicolumn{3}{|c|}{ Alcoholics $(n=50)$} & \multicolumn{3}{|c|}{ Non-alcoholics $(n=50)$} & \multirow{2}{*}{$p$ value } \\
\hline & Abnormal (in \%) & Mean $(\sigma)$ & Range & Abnormal (in \%) & Mean $(\sigma)$ & Range & \\
\hline $\lg E(I U / L)$ & 92 & $1389(3276)$ & $45-8696$ & 24 & $100(94)$ & $17-435$ & $<0.0001$ \\
\hline $\lg G$ (mg/dl) & 54 & 1957 (624) & 993-3606 & 15 & $1909(613)$ & $793-3936$ & 0.697 \\
\hline $\lg A(m g / d l)$ & 26 & $302(114)$ & $103-567$ & 12 & $311(183)$ & $72-113$ & 0.339 \\
\hline $\lg M(m g / d l)$ & 22 & $170(94)$ & $36-373$ & 4 & $144(88)$ & $28-332$ & 0.789 \\
\hline
\end{tabular}

Table 2: Comparison of serum immunoglobulin levels in alcoholics and non-alcoholics.

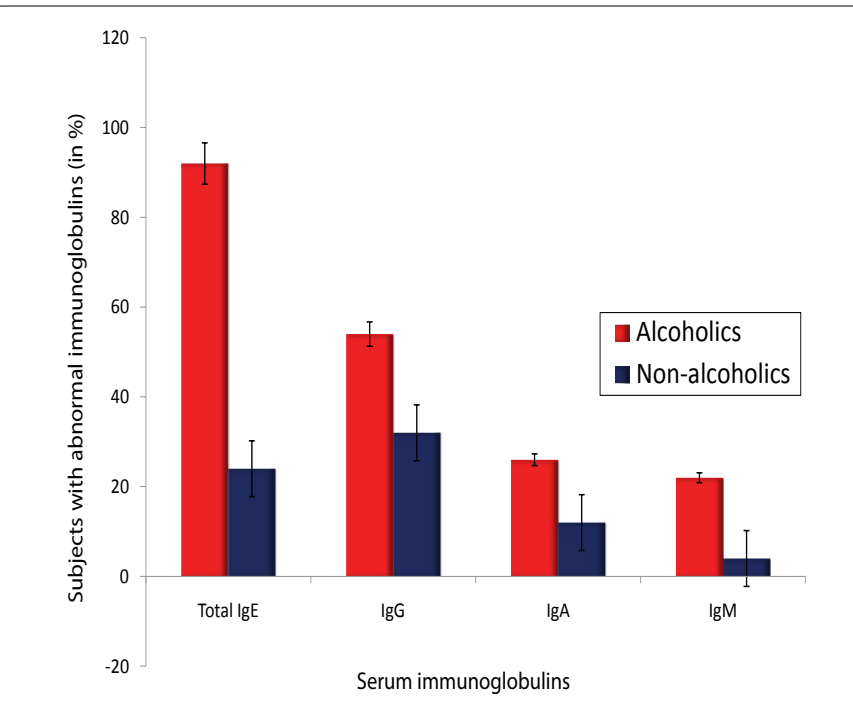

Figure 1: Comparison of serum immunoglobulin levels in the study groups.

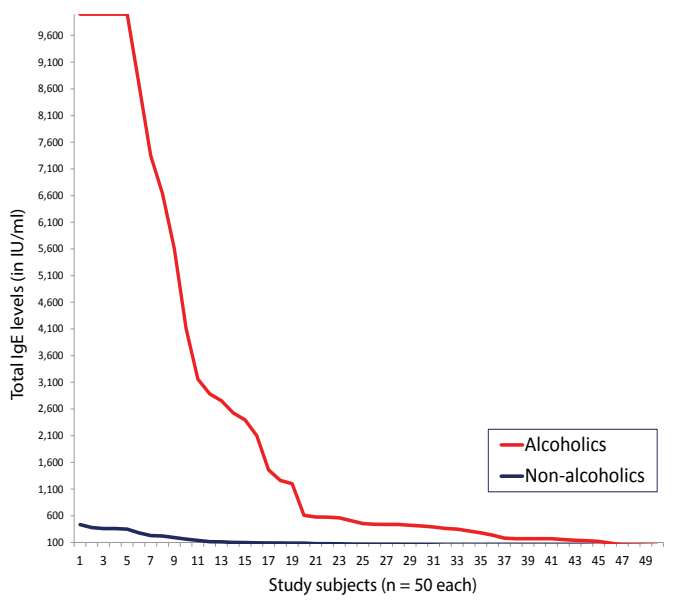

Figure 2: Comparison of individual total IgE values in alcoholics and nonalcoholics. Besides increase in total IgE in alcoholics majority had several fold higher total IgE concentration ( $>1000 \mathrm{IU} / \mathrm{ml}$ ) compared to controls in which levels were much lower $(<500 \mathrm{IU} / \mathrm{ml})$. 
different infections, parasites have been shown to be associated with increased total IgE levels [17]. Though, a possibility of coexisting parasitic infestation in occasional cases cannot be ruled out, an increase of IgE due to parasite in all cases is unlikely. The increased frequency of microbial infection observed in our study could be because of development of secondary immunodeficiency state after prolonged and excessive intake of alcohol as suggested by some Western studies $[18,19]$.

There was a statistically significant association (p-value 0.0001) between alcohol abuse and raised total IgE. Similar to our findings, few other studies have found a relation between alcohol abuse and raised total IgE [10,20-22]. A recent Korean study showed an increased prevalence of allergic sensitization to house dust mite in alcoholics [20]. There are few other studies also suggesting an association between increased IgE and allergic sensitization in alcoholics [22-24]. In control subjects who showed high total IgE levels $(>500 \mathrm{IU} / \mathrm{ml})$, specific IgE levels were measured against common allergens (house dust, tree, and food allergens) to detect an allergic component. Two out of 10 individuals were found to be positive for 1 or more allergens. Both of these subjects had very high total IgE levels $(>10000 \mathrm{IU} / \mathrm{ml})$ and were excluded from the study.

We in our study noted that besides high levels of total IgE, though statistically not significant, IgG, IgA and IgM levels were also increased except a decrease in IgM in a small number of cases. Gluud et al. in their study on patients with alcoholic cirrhosis have also shown occasionally increased levels of IgG, IgA, and IgM [6]. Gonzalez et al. reported deranged IgG and IgM levels and statistically significant rise in IgA levels in alcoholics [8]. McMillan et al. on the other hand, found a decrease in IgG and IgM and an increase in IgA levels in alcoholics and smokers [25]. There are other studies also in which statistically significant increase in IgA was associated with alcohol abuse $[5,23,26]$. In the present study though IgA levels were increased, however, to find out its statistical significance large number of cases need to be studied.

Immunoglobulins are raised once the liver damage has begun, and their values may be directly proportional to the degree of alcoholinduced liver damage. Abnormal immunoglobulin profile may be helpful in predicting the onset and degree of liver damage in alcoholics. Also, there are certain liver disorders, for example, autoimmune hepatitis that also show raised immunoglobulins, particularly IgG [27]. Alcohol abuse may sometimes be confused with such conditions. The results of biochemical tests to assess the degree of liver damage could have helped in better judgment of the association between alcohol abuse and immunoglobulins. Unfortunately liver function tests could not be performed which is a limitation of this study.

In conclusion, a complete panel including IgG, IgA, IgM and IgE may serve as a good laboratory parameter to screen and assess the chronicity of alcohol abuse. It may also be used to avoid confusion with other liver disorders and their misdiagnosis. Further studies, with addition of microbiological and biochemical parameters, if done on larger cohorts may provide additional information on utility of immunoglobulins panel in chronic alcoholics.

\section{Acknowledgements}

The study was supported by the grant from Department of Science and Technology, Chandigarh, India. We are grateful to Ms. Rupali and Mr. Bhuvnesh for their assistance in the study.

\section{References}

1. Laramée P, Brodtkorb T, Rahhali N, Knight C, Barbosa C, et al. (2014) The costeffectiveness and public health benefit of nalmefene added to psychosocial support for the reduction of alcohol consumption in alcohol dependent patients with high/very high drinking risk levels: a Markov model. BMJ Open 4: e005376.

2. Page RM, Page TS (2010) Promoting a tobacco free and drug free lifestyle. 5th edn. In Promoting health and emotional well-being in your classroom: 237-302.

3. Szabo G (1999) Consequences of alcohol consumption on host defense. Alc Alcoholism 34: 830-841.

4. Cook RT (1998) Alcohol abuse, alcoholism and damage to the immune system: a review. Alcoholism 22: 1927-1942.

5. Van de Wiel A, van Hattum J, Schuurman HJ, Kater L (1988) Immunoglobulin $A$ in the diagnosis of alcoholic liver disease. Gastroenterology 94: 457-462.

6. Gluud C, Tage-Jensen U (1983) Autoantibodies and immunoglobulins in alcoholic steatosis and cirrhosis. Acta Med Scand 214: 61-66.

7. Gonzalez-Quintela A, Vidal C, Gude F, Tomé S, Lojo S, Lorenzo MJ, et al (1995) Increased serum IgE in alcohol abusers. Clin Exp Allergy 25: 756-764.

8. Gonzalez-Quintela A, Alende R, Gude F, J Campos, J Rey, et al. (2008) Serum levels of immunoglobulins (IgG, $\lg A, \lg M)$ in a general adult population and their relationship with alcohol consumption, smoking and common metabolic abnormalities. Clin Exp Immunol 151: 42-50

9. Gonzalez-Quintela A, Vidal C, Lojo S, Pérez LF, Otero-Antón E, et al. (1999) Serum cytokines and increased total serum IgE in alcoholics. Ann Allergy Asthma Immunol 83: 61-67.

10. Ray R (2004) The extent, pattern and trends of drug abuse in India: National survey. Ministry of Social Justice and Empowerment, Government of India and United Nations Office on Drugs and Crimes, Regional Office for South Asia.

11. Prasad R (2009) Alcohol use on the rise in India. Lancet 373: 17-18.

12. Jedrychowski WA, Maugeri U, Adamczyk B (1986) Effect of smoking on serum immunoglobulins and cellular blood constituents in healthy individuals. $G$ Ita Med Lav 8: 53-56.

13. Warren CP, Holford-Strevens V, Wong C, Manfreda J (1982) The relationship between smoking and total immunoglobulin $\mathrm{E}$ levels. J Allergy Clin Immuno 69: $370-375$

14. Andersen P, Pedersen OF, Bach B, Bonde GJ (1982) Serum antibodies and immunoglobulins in smokers and nonsmokers. Clin Exp Immunol 47: 467-473.

15. Bahna SL, Heiner DC, Myhre BA (1983) Immunoglobulin E pattern in cigarette smokers. Allergy 38: 57-64.

16. Gorczyca D, Prescha A, Szeremeta K (2015) Impact of Vegetarian Diet on Serum Immunoglobulin Levels in Children. Clin Pediatr 52: 241-246.

17. Nagaraj S, Raghavan R, Macaden R, Kurpad AV (2004) Intestinal parasitic infection and total serum IgE in asymptomatic adult males in an urban slum and efficacy of anti-parasitic therapy. Ind J Med Microbiol 22: 54-56.

18. Friedman $\mathrm{H}$, Newton $\mathrm{C}$, Klein TW (2003) Microbial infections, immunomodulation and drugs of abuse. Clinical Microbiol Rev 16: 209-219.

19. Moss M (2005) Epidemiology of sepsis: race, sex, and chronic alcohol abuse. Clin Infect Dis 41: S490-S497.

20. Kang JW, Baek SH, Rha MS, Kim JH (2014) The effects of alcohol consumption and smoking on allergy risk in Korean adults. Am J Rhinol Allergy 28: e35-e39.

21. Hällgren R, Lundin L (1983) Increased total serum IgE in alcoholics. Acta Med Scand 213: 99-103.

22. Linneberg A, Petersen J, Nielsen NH, Madsen F, Frølund L, et al. (2003) The relationship of alcohol consumption to total immunoglobulin $E$ and the development of immunoglobulin $E$ sensitization: the Copenhagen Allergy Study. Clin Exp Allergy 33: 192-198

23. Gonzalez-Quintela A, Garrido M, Gude F, Campos J, Linneberg A, et al. (2008) Sensitization to cross-reactive carbohydrate determinants in relation to alcoho consumption. Clin Exp Allergy 38: 152-160.

24. Karvonen J, Poikolainen K, Reunala T, Juvakoski T (1992) Alcohol and Smoking: Risk factors for infectious eczematoid dermatitis? Acta Derm Venereol 72: 208-210.

25. McMillan SA, Douglas JP, Archbold GP, McCrum EE, Evans AE (1997) Effect of low to moderate levels of smoking and alcohol consumption on serum immunoglobulin concentrations. J Clin Pathol 50: 819-822. 
Citation: Kumar Y, Lakshmi PVM, Minz RW, Chhabra S, Saikia B (2015) Evaluation of Serum Immunoglobulins IgG, IgA, IgM and Total IgE in Chronic Alcoholics: A Community-based Study. Immunochem Immunopathol 1: 102. doi: 10.4172/2469-9756.1000102

Page 5 of 5

26. Amila M, Rusmir M, Besim P, Aida K (2012) Evaluation of serum IgG, IgM, IgA and $\mathrm{IgE}$ levels in patients with chronic liver diseases. Med $\mathrm{J}$ 18: 81-86.
27. Fallatah HI, Akbar $\mathrm{HO}$ (2010) Elevated serum immunoglobulin $\mathrm{G}$ levels in patients with chronic liver disease in comparison to patients with autoimmune hepatitis. Libyan J Med 5: 10. 